\title{
Analyzing Control and Management of Pile Foundation Cost
}

\author{
Wang Chong \\ Department of Engineering Management \\ Jiangxi College of Foreign Studies, 291, Tian Xiang Street \\ Nan Chang City, China \\ 908319865@qq.com
}

\begin{abstract}
The Pile foundation project is an important component of a construction project and its cost is easily affected by many factors. Therefore, this paper firstly introduces the connotation and significance of controlling the cost of enterprises' foundation project, and then deeply analyzes the main factors that affect engineering cost. Based on the main factors, this paper puts forward some targeted methods of controlling to achieve the purpose of controlling engineering cost.
\end{abstract}

Keywords-pile foundation; project cost; influence factors; control measures

\section{INTRODUCTION}

Pile (pile foundation) is not only an important part of the modern construction but also frequently used in poor geological conditions and construction with higher requirements. As on April 9, 2015, the Wuhan institution of Bridge tested the pile foundation of Bangladesh Bridge in our country. The result of the first tested reinforcement cage which is above water that is placed in the right position means that the controlling project of the trans Asian railway's construction has entered a substantive stage. With the development of the progress of the project Pile, the quality and technology of foundation engineering will become more strict and slashing. Especially, as the basis for the construction of the pile foundation, its cost is the majority of the total cost, and it has significant impact on the benefit of the construction side. The testing of 26 piles of Bangladesh Padma bridge brings about 20000000 Yuan for Wuhan institution of Bridge. However, the pile foundation engineering are generally in the underground, that the geological condition is not stable, and it not only affects the quality of the project, but also puts forward higher requirements on controlling the project cost.

\section{THE CONNOTATION AND SIGNIFICANCE OF CONTROLLING THE COST OF ENTERPRISE's FOUNDATION PROJECT}

\section{A. The connotation of Project Cost}

The construction project cost is enterprises' total cost in the process of project construction, such as construction workers' wage, cost of materials, management, and may other additional charges.

\section{B. The meaning of controlling the cost of enterprises' foundation project}

The controlling of the construction project's cost for enterprises means making the cost of the construction project reasonable, it includes the price of estimating investment, making-up price, final accounts and so on. Besides, on the basis of managing targeted cost, correcting the deviation at any time can achieve the purpose of rational using of manpower, materials and financial resources in the construction project.

With the development of technology, the pile foundation engineering is widely applied, in the ancient wood piles and in the modern bored piles, such as steel pipe piles, precast piles and so on. The pile foundation engineering is a kind of underground engineering, once it is completed and accepted, it will be covered in soil. The cost of a pile foundation takes generally 5-28 percent of the construction's cost. If it is in the soft soil area, the percentage will be bigger. To strengthen the cost controlling of the construction project, controlling the pile foundation engineering is the first step. Analyze the influencing factors of how to manage the pile foundation engineering, then control the cost that used in the process of the pile foundation project. This will be good for implementing construction and the development of enterprises.

\section{ANALYSIS OF THE MAIN FACTORS WHich INFLUENCE THE PRoJEct Cost of THE PILE Foundation}

\section{A. Internal Factors}

\section{1) Macro factors}

For the main phases of the construction of the project, like decision-making, design, implementation and completion and production phase, the biggest influence on the project is from designing phase, which takes $70 \%$ of the project cost, also it is the most key link for the cost control of pile foundation.

The main factors which influence the pile foundation's project cost is as follows: one is the engineering designers' professional level, in order to simplify the pursuit of the safety of pile foundation or deformation requirement, part of the engineering designers' regardless of the cost increase or the length of the section size, will cause huge waste; The second is the accuracy of the engineering geological investigation data. Pile foundation belongs to take cover engineering, underground engineering geological environment changes like the degree of rock weathering, underground water erosion. In the process of 
survey, intensive designers' points extent will affect the quality of pile foundation engineering. Such as the third design institute of China aviation industry in geological exploration, played 17 drilling, 221 meters of penetration, collected 10 samples of different soil for laboratory analysis, the cost of pile foundation is rather large.

In addition, the project bidding documents, the terms of the contract, the quantity change degree of difficulty, the technology of construction and so on all affect pile foundation project cost.

\section{2) The micro factors}

The micro factors of pile foundation project cost refer to some specific factors in the process of pile foundation engineering management, such as labor, materials, and the influence caused by the cost of construction machine's application.

First of all, the artificial expense proportion of engineering cost is bigger, especially in recent years, prices continue to rise, front-line construction workers' average salary is nearly ten thousand Yuan a month. How to ensure sufficient labor and in the same time reduce artificial cost will become the important question of pile foundation project cost controlling. Secondly, in the pile foundation engineering, material cost also occupies a large proportion, any material change will affect the cost of the pile foundation engineering. Such as on January $10^{\text {th }}$, 2008, steel price was 4940 Yuan per ton, but on January of 2015, the price dropped to 3400 Yuan per ton. Due to the longer span of the construction projects, the main building materials price changes will cause serious deviation of pile foundation engineering cost.

\section{B. The External Influencing Factors}

\section{1) Regional differences}

In different provinces, cities and areas, the provisions of the calculation of engineering quantities and the rate of consumption are different, such as the cost of materials and machines, the rate was $4.78 \%$ in Nanchang, 3.2\% in Shenzhen, the enterprise management fee in Fuzhou is $8 \%$. At the same time, the material price and labor cost of different regions are also different, such as in July 2009 to June 2010, the price of concrete used in construction shall not exceed $30 \mathrm{yuan} / \mathrm{m}^{3}$ in Guangzhou, 40 yuan $/ \mathrm{m}^{3}$ in Fuzhou; The labor cost is high in Beijing, Shanghai and Guangdong, The artificial material prices remains 30 Yuan in Nanchang, 44-52 Yuan in Beijing, 53-58 Yuan in Shenzhen.

\section{2) Valuation changes}

The current valuation methods of project cost mainly include list valuation and quota valuation. List valuation is a fully competitive market price, its core is that the construction enterprise according to their level of management, the characteristics of the project, the market supplying situation and the foreseeable risks, to independently offer by the quantities to be supplied by the owner. Quota valuation is a kind of production of planned economic system, its core is the cost management mechanism according to the average level of social determination of each procedure manual labor consumption, material consumption and mechanical affecting consumption, and based on this kind of consumption and price level to determine the unit price of each working procedure. The unit price guiding by the government is known as the fixed price. On the basis of the fixed unit price, according to the project characteristics, the degree of difficulty of construction and construction enterprise management level to determine the project management fees and profits, finally take tax according to relevant national standard and get the project total cost from the summary. The two ways are commonly used in the construction industry in our country.

The denominated in different ways, pile foundation total cost will change too. Compared with the method of list valuation, the method of quota valuation gets the higher cost because it uses the average social advanced level. However, the list valuation uses enterprise independent pricing. In order to adapt to the fierce market competition, enterprise will tend to increase the production efficiency, reduce costs. Therefore, choosing the way of list valuation can achieve the purpose of reducing the cost of pile foundation

\section{Controlling Method of the Pile Foundation PROJECT Cost}

The pile foundation project is not only applicable to any rock stratum, but also to the over-water environment. The cross-section shape of the pile foundation can be a circle and a quincunx form, or can be hollow or solid. Different geological conditions can choose different vertical piles and inclined piles, whereas it still appears different pile foundation project cost, which has drawn the attention of the construction units.

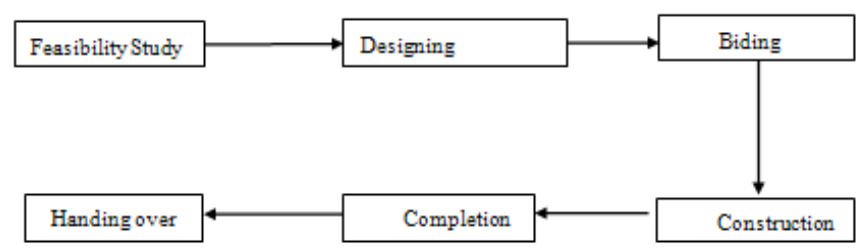

Fig. 1. Flow Chart: Management of Pile Foundation Cost.

\section{A. Macroscopic Means}

1) To strengthen project cost management in designing process

The designing process of the Pile Foundation is very crucial. It concerns the processing of the overall situation and the details and it is also important for reducing the cost of the pile foundation project. It means that if the design is reasonable, it will reduce the cost, whereas if the design is unreasonable, it will raise the cost. Therefore, only optimizing the design plan of the pile foundation project, fully controlling the construction condition and strengthening the audit efforts, can it achieve the maximum economic benefits.

\section{2) To formulate reasonable bidding strategy}

First, attach great importance to making the bidding documents. Stipulate the mode of payment of the pile foundation project and then rationally select and regulate construction period of the project on the basis of making sense of the market quotation; Secondly, in the process of bidding, 
the construction units of the pile foundation project must elect limited price policy, contrast the bid project's demand and its own circulating fund, and then rationally confirm the scope of bidding funds in order to guarantee a certain profit space.

\section{3) To Reasonably supervise the project construction}

The implementation stage of the Pile Foundation Project is a major stage of the consumption of human sources, wealth and goods. Due to the concealment and complexity of the pile foundation project, there is always unexpected cost in the implementation process. Thus, in the implementation stage, what should be done firstly is to perfect the implementation plan, detailing the material and equipment's price changes, the fluctuation of the market supply and demand, etc. It needs not only to reasonably organize the implementation of the pile foundation project, but also to strengthen the management of the implementation stage, in order to realize the Omni bearing and entire control of its implementation.

4) To strengthen the attention of completion settlement audit

After completing the pile foundation project, the construction unit will prepare the construction materials to ask the project owner if its cost ever accords with the provisions of the contract. Therefore, actually completion settlement cost is the actual price of the pile foundation project. In the settlement process, the staff should not only review the construction map, joint trial record, design changes, on-site visa and other technical data, but also carefully examine and verify the economic materials such as bills of quantities, the bidding documents and price lists of the materials. It should prevent the over-calculation and recalculation from happening.

\section{B. The Microcosmic Measures}

1) To attach great importance to the material quality, and strictly control the purchase and custody work

The materials of the pile foundation project changes in the market. Any enterprise cannot effectively control them. As a result, in the process of purchase, the first is to ensure the quality of the material, next to "shop around" to make a better choice. For example, purchasing a large machine adopts the bidding method to admit the best. Other major materials, such as steel and concrete, in accordance with the construction process, can be purchased in batches. The enterprise needs to complete the cost prediction so as to reduce the cost of pile foundation project.

\section{2) To strictly control the design changes and visa}

The pile foundation project is a part of the construction project. Due to external factors such as drawings' design flaw or owners' requirements, pile foundation project will appear design changes and visas. The construction unit should followup at the scene of the pile foundation project, check the authenticity, integrity, and reliability of the design changes and visas. If it really needs to change the pile foundation project, it should be found as early as possible so as to reduce the loss, choose the most economic and feasible scheme and reduce the cost of pile foundation project.

3) To make a rational choice in accordance with the characteristics of pricing

Different pricing methods have important influence on the total cost of pile foundation engineering. The data shows that the same pile foundation project respectively adopts the list valuation method and quota valuation method. The quota valuation method over-calculates about $0.64 \%$ of the amount of cost than the list valuation method. In addition, the evaluation time, the project's contract form and the payment method will affect the valuation methods, so they should be chosen carefully.

\section{CONCLUSIONS}

The cost control of the Pile foundation project plays important role in construction units' construction and the enterprises' sustainable and healthy development. Thus, at the construction scene of the pile foundation project, the construction unit not only needs to do a good job of collecting information of material price, understanding the market changes, and making a bid team at the beginning of the project, but also in the stage of completion to submit the materials, improve the level of cost personnel actively, so as to control the pile foundation project cost.

\section{REFERENCES}

[1] J.S. Wei \& J.H. Zhao, “Analysis on common quality defects of pile foundation. Henan Build. Mater.” vol. 2005, no. 1, pp. 62-63, 2005.

[2] C. Liu, "Analysis of factors affecting the cost of pile foundation and engineering cost control Submission of your recent original work." China Manag. Inform. vol. 2015, no. 2, pp. 30, $2015 .$.

[3] J.T. Zhou \& Y. Tao, "Effect factors and development measures of enterprise engineering cost.” Jiangxi Build. Mater. vol. 2015, no. 1, pp 221, 2015..

[4] H. Zhou, "Analyzing the Influential Factors of the Pile Foundation Cost and Discussing the Method of Its Control and Management," Nanchang University Master Thesis. 32-73, 2010.

[5] W.J. Zhu, "Cost control strategy of project cost management and completion settlement stage.” Jiangxi Build. Mater. vol. 2015, no. 2, pp. 218, 2015. 